\title{
ERRATUM
}

\section{Erratum to: The impact of disability in survivors of critical illness}

\author{
Carol L. Hodgson 1,2,3,4*0D, Andrew A. Udy 2,3,4, Michael Bailey ${ }^{1,3,4}$, Jonathan Barrett ${ }^{4,5}$, Rinaldo Bellomo ${ }^{1,3,6}$, \\ Tracey Bucknall 2,7, Belinda J. Gabbe 3,4, Alisa M. Higgins ${ }^{1,3,4}$, Theodore J. Iwashyna 1,3,8, Julian Hunt-Smith', \\ Lynne J. Murray 1,2,3,4, Paul S. Myles 2,3,4, Jennie Ponsford ${ }^{3,4}$, David Pilcher 1,2,3,4, Craig Walker ${ }^{10}$, \\ Meredith Young ${ }^{1,2,3,4}$ and D. J. Cooper ${ }^{1,2,3,4}$
}

(C) 2017 Springer-Verlag GmbH Germany and ESICM

\section{Erratum to: Intensive Care Med (2017) 43:992-1001 DOI 10.1007/s00134-017-4830-0}

In the Results section, under the subheading "Return to work or usual activities", the second sentence should read:

"At 6 months after ICU, 64 of 262 (25\%) had not returned to work or studies because of their health".

In the original publication, the authors mistakenly used the number in their cohort who were working prior to the ICU admission $(n=107)$ rather than using the total cohort $(n=262)$. The rest of the data, including Table 3 , are correct.

\section{Author details}

${ }^{1}$ Australian and New Zealand Intensive Care Research Centre, Melbourne, Australia. ${ }^{2}$ The Alfred Hospital, Melbourne, Australia. ${ }^{3}$ Monash University, Melbourne, Australia. ${ }^{4}$ Monash Partners Academic Health Science Centre, Prahran, Australia. ${ }^{5}$ Cabrini Hospital, Melbourne, Australia. ${ }^{6}$ Austin Health, Melbourne, Australia. ${ }^{7}$ Deakin University, Geelong, Australia. ${ }^{8}$ University of Michigan, Michigan, USA. ${ }^{9}$ Epworth Health, Melbourne, Australia. ${ }^{10}$ Monash Medical Centre, Melbourne, Australia.

Published online: 15 September 2017

\footnotetext{
*Correspondence: carol.hodgson@monash.edu

${ }^{1}$ Australian and New Zealand Intensive Care Research Centre, Melbourne, Australia
}

Full author information is available at the end of the article

The online version of the original article can be found under doi:10.1007/s00134-017-4830-0.

\section{黛 Springer}

